Gut, 1986, 27, 293-299

\title{
Human colonic smooth muscle: electrical and contractile activity in vitro
}

\author{
R C GILL, K R COTE, K L BOWES, AND Y J KINGMA \\ From the Departments of Surgery and Electrical Engineering, University of Alberta, Edmonton, Alberta, \\ Canada
}

SUMMARY Extracellular electrical and contractile activities were recorded in vitro from strips of human colonic smooth muscle obtained at the time of surgery. Serosal electrical activity of longitudinally oriented strips from the taenia and intertaenial region was characterised by continuous oscillation at a frequency of $28 \mp 1 / \mathrm{min}$. Contractions were marked electrically by a series of oscillations upon which spikes were superimposed. The electrical activity recorded from the submucosal surface of circularly oriented strips exhibited oscillations at $24 \mp 4 / \mathrm{min}$, a frequency significantly lower $(\mathrm{p}<0 \cdot 001)$ than that recorded from the serosal surface of similar preparations. The contractile force and frequency was dependent upon the part of the colon from which the strip originated; the most powerful contractions were recorded from strips of sigmoid colon. The contractile frequency of circularly oriented strips from the right colon was $6 \cdot 3 \mp 0 \cdot 6 / \mathrm{min}$, significantly higher $(\mathrm{p}<0 \cdot 001)$ than that of strips from the left colon $(3 \cdot 4 \mp 0 \cdot 3 / \mathrm{min})$. Stretching these strips caused an increase in contractile frequency to that of the electrical oscillation.

The electrical activity of gastric and small intestinal smooth muscle is well documented and generally accepted as a primary control mechanism of motor activity. ${ }^{12}$ The electromechanical properties of guinea pig, ${ }^{3}$ rabbit, ${ }^{45}$ pig, ${ }^{6}$ cat $^{78}$ and dog $^{9}$ colon have been extensively studied whilst those of human colonic smooth muscle remain ill defined. Human colonic slow waves have been recorded in vivo from serosal, ${ }^{10-12}$ intraluminal ${ }^{10}{ }^{13-17}$ and cutaneous $^{12}$ electrodes. Slow waves have been described as being intermittently ${ }^{121315}$ or continuously ${ }^{18}$ present at two or more frequencies in the ranges of $2-6 / \mathrm{min}$ and $9-16 / \mathrm{min}$; the occurrence or frequency of the slow waves varying along the length of the colon. ${ }^{101218}$ The correlation between contractile activity, as evidenced by increases in intraluminal pressure, and electrical slow wave or spike activity has not been consistent. ${ }^{10-15}$ The results of these in vivo studies are, currently, difficult to reconcile with the electromechanical properties of human colonic smooth muscle in vitro.

In vitro studies of human colonic electrical activity

Address for correspondence: Dr Richard Gill, Department of Surgery, 12-118 Clinical Sciences Building, University of Alberta, Edmonton, Alberta, Canada T6G 2GE.

Received for publication 28 June 1985. have recorded electrical oscillations from taenia coli at a frequency of $17-36 / \mathrm{min}$ using both extracellular ${ }^{19-22}$ and intracellular ${ }^{19} 2122$ recording techniques. Spikes superimposed on these oscillations have been correlated with contractile events. ${ }^{19-22}$ The electrical activity of the circular muscle layer is less clear, electrical oscillations at $2 \cdot 4 / \mathrm{min},{ }^{21} 2-9 / \mathrm{min},{ }^{23}$ and $4 \cdot 5-60 / \mathrm{min}^{22}$ have been reported. Electrical oscillations both with ${ }^{21} 22$ and without ${ }^{22}$ superimposed spikes have been correlated with contractile activity. The electrical and mechanical activities of the longitudinal muscle between the taenia have not been established although a study of tubular colonic segments reported that electrical oscillations originating in the taenia coli could be recorded from the intertaenial longitudinal muscle layer. ${ }^{20}$

This present in vitro study was initiated to determine the extracellular electrical activity that could be recorded from the serosal and submucosal surfaces of human colonic smooth muscle and to correlate the electrical activity with contractile events. Variations in electrical and mechanical characteristics between strips of smooth muscle obtained from different parts of the human colon were assessed. 


\section{Methods}

EXPERIMENTS

In this series of experiments, strips of human colonic smooth muscle, obtained at the time of surgery, were studied in vitro. The surface electrical and mechanical activity of this tissue was recorded.

\section{Tissue acquisition}

Tissue was obtained from 29 patients undergoing partial colectomy for carcinoma or diverticular disease. After resection of the diseased portion, a ring of colon (approximately $2.5 \mathrm{~cm}$ in length) was removed from either the proximal or distal region of the future anastomotic site; the blood supply of this segment being maintained until the moment of excision. Specimens were immediately placed in oxygenated Krebs-Ringer solution. Nine specimens from ascending, eight from transverse, five from descending and seven from sigmoid colon were so obtained.

\section{Tissue preparation}

The colonic segments were opened along the border of a taenia, carefully cleaned to prevent soiling of the muscle layers with faecal content, and pinned to the Sylgard surface of a dissecting dish filled with oxygenated Krebs-Ringer solution. The mucosa was removed by sharp dissection. Strips of smooth muscle were cut with the long axis lying in the direction of the muscle fibres. Longitudinally oriented strips $(2.0 \times 0.4 \mathrm{~cm})$ were obtained both from the taenia (mean weight $248 \mp 52 \mathrm{mg}$ ) and the region between the taenia (mean weight $158 \mp 27 \mathrm{mg}$ ). Circularly oriented strips $(1.5 \times 0.4 \mathrm{~cm})$ were taken from the intertaenial region (mean weight $123 \mp 39 \mathrm{mg}$ ). Strips were mounted in a horizontal tissue chamber maintained at $37 \mp 1^{\circ} \mathrm{C}$ and continuously superfused with oxygenated Krebs-Ringer solution.

\section{Recording techniques}

Electrical activity was recorded from the serosal (longitudinally oriented strips) or submucosal (circularly oriented) surface using either one (monopolar recording) or two (bipolar recording) electrodes on each strip. Two types of electrode were used [1] low-noise, low-drift silver-silver chloride $(\mathrm{Ag} / \mathrm{AgCl})$ pressure electrodes ${ }^{24}$ and [2] platinised platinumirridium (Pt-Pt/Ir) electrodes which had a lower impedance than the $\mathrm{Ag} / \mathrm{AgCl}$ electrodes at frequencies $<0.25 \mathrm{~Hz}$ (unpublished observation). The macroscopic surface area of the $\mathrm{Ag} / \mathrm{AgCl}$ electrodes was $0.46 \mathrm{~mm}^{2}$, whilst that of the Pt-Pt/Ir electrodes was $0.11 \mathrm{~mm}^{2}$. During monopolar recordings, the reference electrodes placed in the superfusing fluid were large $\mathrm{Ag} / \mathrm{AgCl}$ or $\mathrm{Pt}-\mathrm{Pt} / \mathrm{Ir}$ electrodes respectively. During bipolar recordings, the electrodes were placed $5.0 \mathrm{~mm}$ apart on the surface of the smooth muscle strip.

Contractile activity of the muscle strips was recorded with a force displacement transducer (Grass FT03).

Recordings were made of the electrical and mechnical activity on a Beckman R411 polygraph; for the electrical activity, filters were set to give a low frequency cut off at $0.06 \mathrm{~Hz}$ (modified 9806A couplers) and a high frequency cut off at $30 \cdot 0 \mathrm{~Hz}$.

\section{Solutions}

The superfusate used was modified Krebs-Ringer solution containing the following $(\mathrm{mN}): \mathrm{Na}^{+}, 139 \cdot 2$; $\mathrm{K}^{+}, 5 \cdot 4 ; \mathrm{Ca}^{2+}, 2 \cdot 5 ; \mathrm{Mg}^{2+}, 1 \cdot 2 ; \mathrm{Cl}^{-}, 125 \cdot 1 ; \mathrm{HCO}_{3}^{-}$, $22.0 ; \mathrm{H}_{2} \mathrm{PO}_{4}^{-}, 1 \cdot 2$; glucose, $10 \cdot 1$. When equilibrated with $95 \% \mathrm{O}_{2}, 5 \% \mathrm{CO}_{2}$ gas mixture at $37^{\circ} \mathrm{C}$, this solution had a pH of 7.3-7.4.

\section{Experimental protocol}

Preliminary experiments showed that the contractile activity of human colonic smooth muscle strips was dependent upon the degree of stretch. At the start of each study, basal tension was applied to all strips. This tension varied with the preparation being studied; $7.4 \mathrm{mN}$ for taenial longitudinally oriented strips, $4.9 \mathrm{mN}$ for intertaenial longitudinally oriented strips and $9.8 \mathrm{mN}$ for circularly oriented strips. This applied tension ensured that all strips were studied at approximately $115 \%$ of their initial length, the initial length being defined as the length at which an increase in baseline force was first recorded. Each strip was set at this length for the remainder of the experiment. After a 30 minute equilibration period, during which the strips were superfused with oxygenated Krebs-Ringer solution, the surface electrical and mechanical activities of the muscle strips were recorded for a period of four hours. After the experiment, the strips were removed from the tissue chamber, blotted, and weighed on a balance (Mettler B5) to the nearest $0 \cdot 1 \mathrm{mg}$.

\section{Analysis of data}

Recordings of electrical and mechanical activity were analysed visually. Each hour of study was subdivided into six 10 minute periods which were analysed separately; mean values for each hour of study were then calculated. The force and frequency of contractions and the corresponding electrical activity were assessed for each smooth muscle strip. Mean contractile force exerted by the muscle strips was expressed per $\mathrm{mg}$ of strip weight. 
STATISTICAL ANALYSIS

Throughout this study, results have been expressed as the mean Fone standard deviation of the mean. Statistical significance of the results was determined using Student's $t$ test.

\section{Results}

In general, monopolar and bipolar recordings of extracellular electrical activity obtained from $\mathrm{Ag} /$ $\mathrm{AgCl}$ or Pt-Pt/Ir electrodes were comparable; bipolar recordings from $\mathrm{Pt}-\mathrm{Pt} / \mathrm{Ir}$ electrodes tended to be more stable, less 'noisy' and of greater amplitude.

\section{TAENIAL LONGITUDINALLY ORIENTED STRIPS}

The extracellular electrical activity recorded from all 34 strips of taenia coli studied was characterised by continuous oscillation at a frequency of $27.8 \mp 1.2 / \mathrm{min}$ (range $23-31 / \mathrm{min}$ ). The frequency of oscillation was not significantly different $(p>0.4)$ between strips obtained from different parts of the colon (Table) and did not vary significantly $(p>0.4)$ over the four hour study period.

Contractile activity of these strips was marked, electrically, by a series of larger amplitude oscillations upon which spikes were superimposed; an increment of tension being associated with each spike (Fig. 1a). The force and frequency of these contractile events was dependent upon the portion of the colon from which the taenia was obtained (Table). Strips of taenia obtained from the ascending colon contracted with a significantly greater ( $>0.005$ ) force than those obtained from transverse, descending or sigmoid colon. The contractile frequency of strips obtained from the ascending or transverse colon was significantly higher $(p<0.025)$ than that of strips obtained from the descending or sigmoid colon. Neither the contractile force or

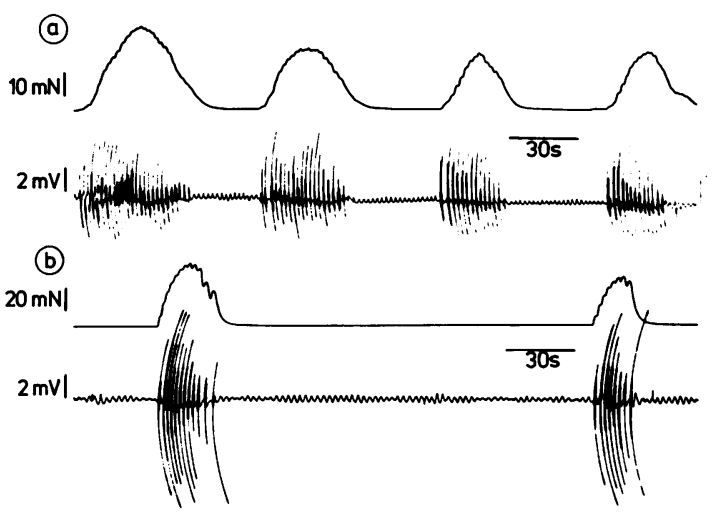

Fig. 1 Contractile (upper panels) and serosal electrical (lower panels) activities of taenial $(A)$ and intertaenial $(B)$ logitudinally oriented strips of smooth muscle obtained from the transverse colon. Electrical activity recorded with bipolar Pt-Pt/Ir electrodes.

frequency of the taenial strips varied significantly $(p>0 \cdot 25)$ over the four hour study period.

\section{INTERTAENIAL LONGITUDINALLY ORIENTED}

STRIPS

Twenty eight strips of intertaenial longitudinal smooth muscle were studied. The extracellular electrical activity recorded from these strips was characterised by continuous oscillation at a mean frequency of $28 \cdot 6 \mp 1 \cdot 1 / \mathrm{min}$ (range $25-33 / \mathrm{min}$ ); this was not significantly different $(p>0.25)$ from that recorded from the taenial strips. The oscillatory frequency was not significantly different $(p>0.4)$ between strips obtained from different parts of the colon (Table) and did not alter significantly $(p>0.4)$ over the four hour study period. Contractile activity of these strips was marked, electrically, by a series of larger amplitude oscillations upon which spikes were superimposed; an increment of tension being

Table Electrical and contractile activity of human colonic smooth muscle in vitro

\begin{tabular}{|c|c|c|c|c|}
\hline Part of colon & Ascending & Transverse & Descending & Sigmoid \\
\hline \multicolumn{5}{|c|}{ Taenial longitudinally oriented strips } \\
\hline Contractile force $(\mathrm{mN} / \mathrm{mg})$ & $0 \cdot 43 \pm 0 \cdot 16$ & $0 \cdot 18 \pm 0.05$ & $0 \cdot 21 \pm 0 \cdot 07$ & $0 \cdot 19 \pm 0 \cdot 08$ \\
\hline Contractile freq/min & $0 \cdot 74 \pm 0 \cdot 20$ & $0 \cdot 86 \pm 0 \cdot 15$ & $0 \cdot 57 \pm 0 \cdot 19$ & $0 \cdot 57 \pm 0 \cdot 14$ \\
\hline Electrical $\mathrm{freq} / \mathrm{min}$ & $27 \cdot 5 \pm 1 \cdot 9$ & $28 \cdot 3 \pm 1 \cdot 0$ & $27 \cdot 8 \pm 1 \cdot 1$ & $27 \cdot 9 \pm 1 \cdot 1$ \\
\hline \multicolumn{5}{|c|}{ Intertaenial longitudinally oriented strips } \\
\hline Contractile force $(\mathrm{mN} / \mathrm{mg})$ & $0 \cdot 51 \pm 0 \cdot 19$ & $0.41 \pm 0.09$ & $0.44 \pm 0.08$ & $0.49 \pm 0.06$ \\
\hline Contractile freq $/ \mathrm{min}$ & $0 \cdot 18 \pm 0 \cdot 04$ & $0 \cdot 21 \pm 0 \cdot 12$ & $0 \cdot 54 \pm 0 \cdot 12$ & $0 \cdot 53 \pm 0 \cdot 15$ \\
\hline Electrical $\mathrm{freq} / \mathrm{min}$ & $29 \cdot 0 \pm 1 \cdot 1$ & $28 \cdot 3 \pm 0 \cdot 9$ & $28 \cdot 4 \pm 1 \cdot 0$ & $29 \cdot 0 \pm 1 \cdot 5$ \\
\hline \multicolumn{5}{|c|}{ Intertaenial circularly oriented strips } \\
\hline Contractile force $(\mathrm{mN} / \mathrm{mg})$ & $0.05 \pm 0.02$ & $0.04 \pm 0.02$ & $0.05 \pm 0.01$ & $0 \cdot 10 \pm 0 \cdot 04$ \\
\hline Contractile freq/min & $6 \cdot 51 \pm 0 \cdot 52$ & $4 \cdot 68 \pm 1 \cdot 52$ & $3 \cdot 23 \pm 0 \cdot 34$ & $3 \cdot 48 \pm 0 \cdot 16$ \\
\hline Electrical $\mathrm{freq} / \mathrm{min}$ & $23 \cdot 8 \pm 3 \cdot 9$ & $23 \cdot 1 \pm 4 \cdot 0$ & $24 \cdot 0 \pm 4 \cdot 4$ & $23 \cdot 1 \pm 4 \cdot 3$ \\
\hline
\end{tabular}


associated with each spike (Fig. 1b). The contractile force of intertaenial longitudinally oriented strips obtained from different parts of the colon was not significantly different $(p>0 \cdot 1)$. The contractile frequency of strips obtained from the ascending or transverse colon was, however, significantly lower $(p<0.001)$ than that of strips obtained from the descending or sigmoid colon (Table). Neither the contractile force or frequency of the intertaenial longitudinally oriented strips varied significantly $(p>0.25)$ over the four hour study period.

\section{INTERTAENIAL CIRCULARLY ORIENTED STRIPS}

Extracellular electrical activity recorded from the $\mathbf{5 0}$ circularly oriented strips studied was characterised by continuous low voltage, oscillation at a frequency of $23.8 \mp 3.9 / \mathrm{min}$ (range $14-58 / \mathrm{min}$ ) which was significantly lower $(p<0.001)$ than that recorded from either the taenial or intertaenial longitudinally oriented strips. The frequency of oscillation was not significantly different $(p>0.4)$ between strips obtained from different parts of the colon (Table) and did not vary significantly $(p>0.4)$ over the four hour study period. The spontaenous contractile activity of these strips could not, in general, be correlated with the extracellular electrical activity recorded (Fig. 2). Occasionally ( $<1 \%$ of recording time), however, the surface electrical activity did appear to correlate with contractile events although this was only noted during monopolar recordings and was most likely because of motion artefact (Fig. $3)$. On no other occasion were electrical oscillations recorded at a frequency less than $14 / \mathrm{min}$.

The force and frequency of the continuous contractions recorded from the circularly oriented strips was dependent upon the part of the colon from which the strips were obtained (Table). The contractile force of strips obtained from the sigmoid colon

$$
\text { (a) }
$$

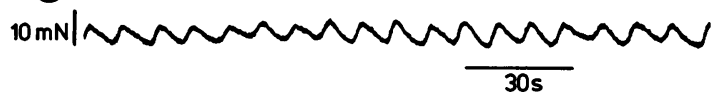

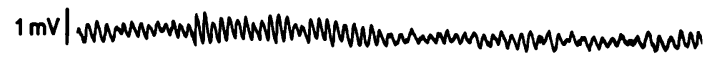

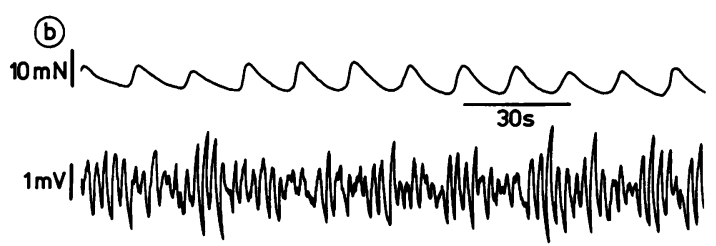

Fig. 2 Contractile (upper panels) and submucosal electrical (lower panels) activities of circularly oriented strips of smooth muscle obtained from the ascending $(A)$ and descending $(B)$ colon.

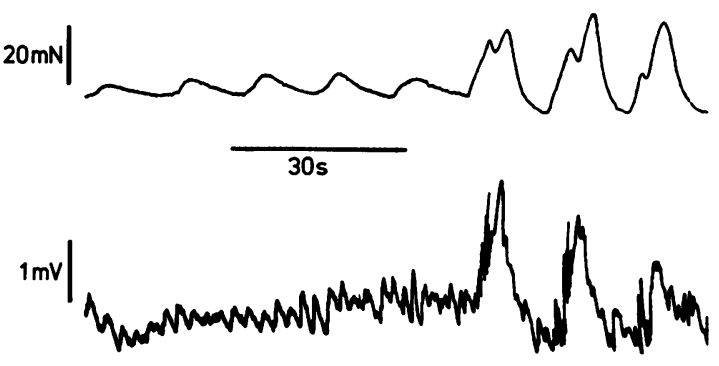

Fig. 3 Contractile (upper panel) and submucosal electrical (lower panel) activities of circularly oriented strip of smooth muscle obtained from the sigmoid colon. Electrical activity recorded with monopolar $\mathrm{Ag} / \mathrm{AgCl}$ electrode; note electrical artefact associated with large-amplitude contractions.

was significantly greater $(p<0.005)$ than that of strips obtained from the ascending, transverse or descending colon. The contractile frequency of strips obtained from the ascending and righttransverse colon was significantly higher $(p<0.001)$ than that of strips from the left-transverse, descending or sigmoid colon (Fig. 4). Neither the contractile force or frequency of the intertaenial circularly

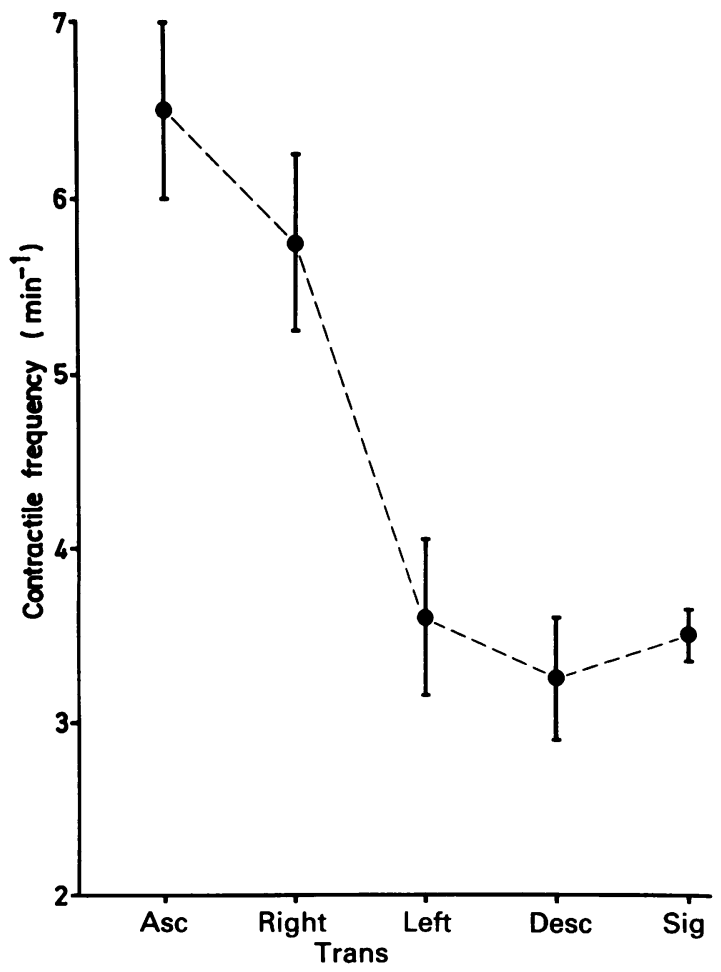

Fig. 4 Contractile frequency of circularly oriented smooth muscle strips obtained from sites along the length of the human colon. 
(a)
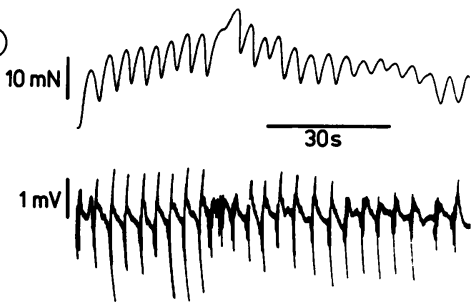

(b)
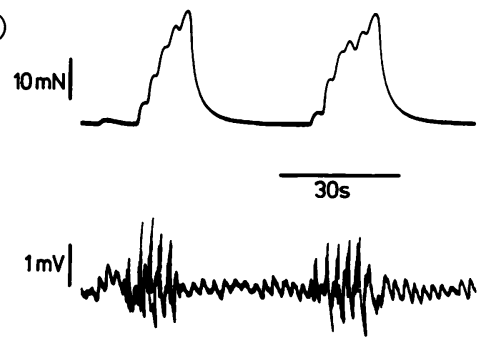

Fig. 5 Contractile (upper panels) and submucosal electrical (lower panels) activities of circularly oriented strip of smooth muscle obtained from the transverse colon to which $40 \mathrm{mN}$ of basal tension had been applied. Contractions were observed at the frequency of the electrical oscillation $(A)$, these contractions could summate and give rise to contractions of long duration $(B)$.

oriented strips varied significantly $(p>0.25)$ over the four hour study period.

The electrical oscillatory frequency of intertaenial circularly oriented strips from any part of the colon was not affected by increasing the basal tension applied. At basal tensions exceeding $30 \mathrm{mN}$, however, spikes were frequently superimposed on the electrical oscillations; the contractile frequency of the strips increasing to that of the electrical oscillation (Fig. 5a). These contractions frequently summated and gave rise to contractions of prolonged duration (Fig. 5b) which recurred at a frequency of $1-3 / \mathrm{min}$.

\section{Discussion}

The electrical activity recorded from the submucosal surface of pig, ${ }^{6}$ cat $^{25}$ and $\operatorname{dog}^{9}{ }^{26}$ colon is marked by rhythmic changes in membrane potential referred to as slow waves. In the feline ${ }^{25}$ and canine ${ }^{26}$ colon, at least, the slow waves appear to originate from the inner circular muscle layer and, as in the stomach and small-intestine, ${ }^{12}$ determine the temporal and spatial relationships of phasic contractions of the smooth muscle. In the human colon, a similar electrophysiological control of contractile activity has been proposed ${ }^{10} 121618$ with the electrical slow waves occurring at a frequency of $2-16 / \mathrm{min}$. Indeed, changes in the incidence of colonic slow waves at a frequency of $3 / \mathrm{min}$ have been correlated with the existence of the irritable colon syndrome, 1427 and chronic non-organic constipation. ${ }^{28}$

In this study, electrical oscillations recorded from the submucosal surface of intertaenial strips of human colonic smooth muscle had a mean frequency of $24 / \mathrm{min}$. These oscillations were thought most likely to originate from the circular muscle layer as they were of significantly lower frequency than those recorded from the serosal surface of similar preparations. This confirms the finding of Huizinga et $a l^{22}$ who recorded electrical oscillation at a frequency of $13-28 / \mathrm{min}$ from resected specimens of sigmoid colon using the sucrose gap technique. These investigators also reported electrical oscillation at a frequency of $<12 /$ min recorded from $50 \%$ of their preparations when using extracellular suction electrodes. We observed electrical oscillations in the frequency range $2-13 / \mathrm{min}$ for $<1 \%$ of recording time in association with marked contractile activity. It would seem likely that these oscillations of $<13 / \mathrm{min}$ represent motion artefact. These motion-related artefacts were most frequently recorded from circularly oriented strips obtained from the sigmoid colon which exerted a greater contractile force than those obtained from other parts of the human colon.

These findings are not consistent with the most frequently reported human colonic slow wave frequencies of $3 / \mathrm{min}$ and $6 / \mathrm{min} .{ }^{29}$ Our failure to detect oscillations $<13 / \mathrm{min}$ was not because of limitations of the recording apparatus, the same equipment and identical filter settings have been used to record the slow wave activity of human gastric and small intestinal smooth muscle; it would seem likely that we should have detected them, if present. In this regard, it is possible that the slow wave frequencies of $3 / \mathrm{min}$ and $6 / \mathrm{min}$ reported in vitro ${ }^{21} 23$ and so commonly in vivo ${ }^{12}{ }^{14-16} 18$ are a reflection of the contractile activity of the colonic smooth muscle rather than its underlying electrical activity. This might be most likely to occur in recordings from the distal colon because of the greater contractile force of circularly oriented smooth muscle strips from the sigmoid colon (present study) and the smaller diameter of the colon. ${ }^{3}$ In the light of these observations, there would appear to be diminishing support for the hypothesis that slow waves recorded in vivo from the human colon in the frequency range of $3-12 / \mathrm{min}$ represent electrical events. Consistent with our observations, however, in vivo studies of the electrical activity of the internal anal sphincter ${ }^{31} 32$ and rectal canal ${ }^{17}$ using intraluminal 
electrodes reported electrical oscillations of $20 / \mathrm{min}$. Electrical oscillations recorded from the submucosal surface of human colonic smooth muscle bore no consistent relationship to the contractile events of the circularly oriented strips; this is in contrast with the results of animal studies. ${ }^{625} 26$ The effect of stretching these strips, however, was to increase the contractile frequency to that of the electrical oscillations suggesting that the electrical oscillations may determine the maximum frequency of contraction. The possibility that multiple pacemakers exist and contribute to the range of frequencies recorded from the submucosal surface of human colonic smooth muscle cannot be excluded.

The serosal electrical activity recorded from strips of human taenia coli was characterised by continuous oscillation at a frequency of $28 / \mathrm{min}$. Spikes superimposed upon these oscillations were correlated with contractile events. This confirms the findings obtained by others using both extracellular $^{19-22}$ and intracellular ${ }^{19} 2122$ recording techniques. This study also reports the serosal electrical and contractile activities of longitudinally oriented strips obtained from the intertaenial region. Electrically, oscillations were recorded from these strips at a frequency which was not significantly different from that of taenial strips, similarly, the superimposition of spikes on these oscillations was correlated with contractile events. It would appear, therefore, that electrical oscillation at a frequency of $23-33 / \mathrm{min}$ is a feature common to both taenial and intertaenial longitudinal smooth muscle, it does not originate solely from the taenia as previously suggested. ${ }^{20}$ Electrical oscillations within this frequency range have, infrequently, been recorded from the human colon in vivo using serosal electrodes implanted at operation. ${ }^{10} 11$ Thus, the electromechanical activity recorded from the longitudinal muscle layer of the human colon appears to resemble that of the pig, ${ }^{6}$ guinea pig, ${ }^{3}$ rabbit $^{4}$ and even the non-taeniated $\operatorname{dog}^{9}$ colon.

Contractile and electrical frequency gradients have been described in the colon of cat, ${ }^{7}$ rabbit $^{5}$ and man. $20233033-35$ We could find no evidence of a gradient in the frequency of electrical oscillation recorded from either the longitudinal or circular muscle layers of strips obtained from different parts of the colon. Circularly oriented strips from the ascending and right transverse colon, however, contracted at nearly twice the frequency of strips from the left transverse, descending or sigmoid colon; a similar finding has been made in vivo. ${ }^{35}$ This evidence in favour of a right-to-left colonic gradient may be related in some way to the differing embryological origin and innervation of these two areas of the human colon.
In summary, we have attempted to define the electrical and contractile activities of human colonic smooth muscle in vitro. Two electrical oscillatory frequencies have been recorded and correlated with contractile events of the longitudinal and circular muscle layers respectively. Slow waves in the frequency range $2-13 / \mathrm{min}$ were not present. The contractile, but not electrical oscillation, frequency of the circular muscle layer appears to decrease in an aboral direction along the colon.

R C Gill was in receipt of an award from the Alberta Heritage Foundation for Medical Research. This work was supported, in part, by the Medical Research Council of Canada. The authors gratefully acknowledge the assistance of the surgeons attached to the Department of Surgery, University of Alberta Hospitals in the acquisition of colonic tissue.

\section{References}

1 Kelly KA. Motility of the stomach and gastroduodenal junction. In: Johnson LR, ed. Physiology of the gastrointestinal tract. New York: Raven Press, 1981: 393-410.

2 Weisbrodt NW. Motility of the small intestine. In: Johnson LR, ed. Physiology of the gastrointestinal tract. New York: Raven Press, 1981: 411-43.

3 Bulbring E, Burnstock G, Holman ME. Excitation and contraction in the smooth muscle of the isolated taenia coli of the guinea-pig. J Physiol 1958; 142: 420-37.

4 Gillespie JS. Spontaneous mechanical and electrical activity of stretched and unstretched intestinal smooth muscle cells and their response to sympathetic-nerve stimulation. J Physiol 1962; 162: 54-75.

5 Snape WJ Jr, Shiff S. Neurohumoral control of colonic motility in the rabbit. Am J Physiol 1983; 245: 582-8.

6 Huizinga JD, Diamant NE, El-Sharkawy TY. Electrical basis of contractions in the muscle layers of the pig colon. Am J Physiol 1983; 254: 482-91.

7 Christensen J, Anuras S, Hauser RL. Migrating spike bursts and electrical slow waves in the cat colon: effect of sectioning. Gastroenterology 1974; 66: 240-7.

8 Weinbeck M, Christensen J, Weisbrodt NW. Electromyography of the colon in the unanesthetized cat. Am J Dig Dis 1972; 17: 356-62.

9 El-Sharkawy TY, Bardakjian BL, MacDonald WM, Diamant NE. Origins of multiple patterns of electrical control activity in the colon. In: Weinbeck $M$ ed. Motility of the digestive tract. New York: Raven Press, 1982: 491-7.

10 Provenzale L, Pisano M. Methods for recording electrical activity of the human colon in vivo. Am J Dig Dis 1971; 16: 712-22.

11 Sarna SK, Waterfall WE, Bardakjian BL, Lind JF. Types of human colonic electrical activities recorded postoperatively. Gastroenterology 1981; 81: 61-70.

12 Taylor I, Duthie HL, Smallwood R, Linkens D. Large bowel myoelectrical activity in man. Gut 1975; 16: 808-14. 
13 Couturier D, Roze C, Couturier-Turpin MH, Debray C. Electromyography of the colon in situ. An experimental study in man and in the rabbit. Gastroenterology 1969; 56: 317-22.

14 Snape WJ Jr, Carlson GM, Cohen S. Colonic myoelectric activity in the irritable bowel syndrome. Gastroenterology 1976; 70: 326-30.

15 Snape WJ, Matarazzo SA, Cohen S. Effect of eating and gastrointestinal hormones on human colonic myoelectrical and motor activity. Gastroenterology 1978; 75: 373-8.

16 Taylor I, Duthie HL, Smallwood R, Brown BH, Linkens $D$. The effect of stimulation on the myoelelectrical activity of the rectosigmoid in man. Gut 1974; 15: 599-607.

17 Wankling WJ, Brown BH, Collins, CD, Duthie HL. Basal electrical activity in the anal canal in man. Gut 1968; 9: 457-60.

18 Sarna SK, Bardakjian BL, Waterfall WE, Lind JF. Human colonic electrical control activity (ECA). Gastroenterology 1980; 78: 1526-36.

19 Duthie HL, Kirk D. Electrical activity of human colonic smooth muscle in vitro. $J$ Physiol 1978; 283: 319-30.

20 Vanasin B, Ustach TJ, Schuster MM. Electrical and motor activity of human and dog colon in vitro. Hopkins Med J 1974; 134: 201-10.

21 van Merwyk AJ, Duthie HL. Characteristics of human colonic smooth muscle invitro. In: Christensen J, ed. Gastrointestinal motility. New York: Raven Press, 1980: 473-8.

22 Huizinga JD, Stern HS, Chow E, Diamant NER, ElSharkawy TY. Electrophysiologic control of motility in the human colon. Gastroenterology 1985; 88: 500-11.

23 Chambers MM, Bowes KL, Kingma YJ, Bannister C, Cote KR. In vitro electrical activity in human colon. Gastroenterology 1981; 81: 502-8.
24 Kingma YJ, Lenhart J, Durdle NG, Bowes KL, Chambers $\mathrm{MM}$. Improved $\mathrm{Ag} / \mathrm{AgCl}$ pressure electrodes. Med Biol Eng Comput 183; 21: 351-7.

25 Christensen J, Caprilli R, Lund GF. Electric slow waves in circular muscle of cat colon. Am J Physiol 1969; 217: 771-6.

26 Durdle NG, Kingma YJ, Bowes KL, Chambers MM. Origin of slow waves in the canine colon. Gastroenterology 1983; 84: 375-82.

27 Taylor I, Darby C, Hammond P, Basu P. Is there a myoelectrical abnormality in the irritable colon syndrome? Gut 1978; 19: 391-5.

28 Frieri G, Parisi F, Corrazziari E, Caprilli R. Colonic electromyography in chronic constipation. Gastroenterology 1983; 84: 737-40.

29 Christensen J. Motility of the colon. In: Johnson LR, ed. Physiology of the gastrointestinal tract. New York: Raven Press, 1981: 445-71.

30 Torsoli A, Ramorino ML, Crucioli V. The relationships between anatomy and motor activity of the colon. Am J Dig Dis 1968; 13: 462-7.

31 Kerremans R. Electrical activity and motility of the internal anal sphincter. Acta Gastroenterol Belg 1968; 31: $465-82$.

32 Ustach TJ, Tobon F, Hambrecht T, Bass DD, Schuster MM. Electrophysiological aspects of human sphincter function. J Clin Invest 1970; 49: 41-8.

33 Bloom A, LoPresti P, Farrar JT. Motility of the intact human colon. Gastroenterology 1968; 54: 232-40.

34 Chauve A, Devroede MD, Bastin E. Intraluminal pressures during perfusion of the human colon in situ. Gastroenterology 1976; 70: 336-40.

35 Kerlin P, Zinsmeister A, Phillips S. Motor responses to food of the ileum, proximal colon and distal colon of healthy humans. Gastroenterology 1983; 84: 762-70. 